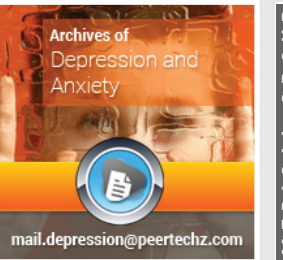

\title{
Bipolar disorder in children and adolescents
}

\section{Michel Bourin*}

Neurobiology of Anxiety and Depression, University of Nantes, 98, rue Joseph Blanchart, 44100 Nantes, France
Received: 11 November, 2020

Accepted: 02 December, 2020

Published: 03 December, 2020

*Corresponding author: Michel Bourin, Neurobiology of Anxiety and Depression, University of Nantes, 98, rue Joseph Blanchart, 44100 Nantes, France, E-mail: michel.bourin@univ-nantes.fr

Keywords: Bipolar disorder; ADHD; Children; Adolescents

https://www.peertechz.com

\section{Abstract}

Bipolar Disorder (BD) in children and adolescents is poorly understood and underdiagnosed. We describe its clinical manifestations, its interweaving of comorbidity with frequent psychopathological manifestations, such as Attention Deficit Hyperactivity Disorder (ADHD), which allows us to outline the prodromes and risk indicators. Depending on the presentation of these indicators, several degrees of clinical risk can be established. Irritability, impulsivity, hyperactivity, frustration intolerance and sleep disturbances are among the most common symptoms. In the presence of a suicidality clinic, drug abuse (cannabis, alcohol), or psychotic symptoms, in a context of significant family history, the child psychiatrist should no longer hesitate to make the diagnosis of bipolar disorder and initiate a consequent treatment.

\section{Introduction}

As early as the $19^{\text {th }}$ century, the possible occurrence of what was then called "periodic and circular madness of exaltation and dejection" during childhood and adolescence was already mentioned by French authors (Falret, Sollier) and Germans (Kraepelin). In the 1930s, Barrett and Kasanin also reported cases of children and adolescents with cycles of euphoric hyperactivity and depression. Finally, in 1960, Anthony and Scott pointed out that it is possible to diagnose, albeit infrequently, states close to bipolar disease in young children, these states being able to be expressed in extreme forms of cheerfulness, hyperactivity and of negativism, or by fantasies of all power and grandeur. Despite these data, since the publication in 1947 of Kanner's Manual of Child Psychiatry, it was recognized that manic depression was hardly ever seen until late adolescence [1].

\section{Clinical signs of bipolarity in children and adolescents}

Childhood and Adolescent Bipolar Disorder is a severe psychiatric condition, primarily hereditary in nature, which causes children to seriously impair their functioning at school, at home and with their peers [2]. It presents a variable and imprecise clinic, with an important comorbidity and symptoms which differ from the $\mathrm{BD}$ of the adults in a mainly quantitative way. One of the clinical difficulties arises from the fact that the current diagnostic criteria (DSM-5, ICD-10) do not include specific diagnostic categories [3].
Pediatric bipolar disorder is not uncommon but difficult to diagnose. A psychiatric disorder can be considered a valid diagnostic entity if it can be shown to have distinct characteristics, a reproducible response to treatment and a specific course [4]. The most frequent symptoms are: hyperactivity, mania or hypomania, ideas of grandeur, irritable mood, aggressiveness, risky behavior, substance abuse, reduced sleep (without fatigue during the day), tachylalia, tachypsychia, difficulty concentrating, hypersexuality, and in some cases auditory hallucinations.

The characteristic symptoms observed retrospectively in these children (aged 1 to 6 years) include mainly irritability and loss of control [5]. They are characterized by the following manifestations: temper tantrums, impulsivity, aggressions, reduced attention span, hyperactivity, irritability and low tolerance for frustration. In a more recent study, the most common symptoms in preschool children (3-7 years) were irritability (84.6\%) and aggression (88.5\%), with most children being referred like hyperactive children. Irritability should be chronic, non-episodic and severe, and aggression excessive [6].

Aggressivity is therefore a common feature of BD, especially in children and adolescents. It was shown that adolescents with mood disorders exhibit affective, reactive and defensive aggressiveness, not intermittently, but very often in the form of escalation [7]. There are many diagnostic scales, the most 
relevant of which are currently being the Mood Disorder Questionnaire Adolescent Version (MDQ-A) [8].

A study of 263 bipolar children and adolescents, aged 7 to 17 (mean age 13), found it to be a chronic disease with a high rate $(56 \%)$ of relapses [9]. Regarding suicidality, another study of 405 subjects of the same age showed that $32 \%$ of patients had a history of suicide attempts. It is likely that the frequency of bipolar disorder in adolescence is underestimated because it can begin as a depressive episode, with schizophrenic symptoms or as a dyssocial disorder (serious conduct disorders, vandalism) [10].

In offspring studies, both bipolar disorder 1 and bipolar disorder 2 have been observed that subjects with a history of bipolar have an earlier onset of disease [11]. Historically, Esquirol had referred in 1838 several cases of manic access in school-aged children, without forgetting that Kraepelin in turn described depressive and manic attacks in children and adolescents. Hypomanic arrays have been described in very young children, around four years old [12]

Some studies tend to show that prepubertal mania is underdiagnosed and that there can be up to $50 \%$ misdiagnosis [13]. However, it is in adolescence that the peak incidence occurs, 20 to $25 \%$ of the onset of the disease before the age of nineteen [14]. In addition, manic pictures are frequent in adolescence without constituting a complete clinical picture. These are closer to schizophrenic pictures, with first order symptoms, auditory or visual hallucinations, referral ideas and manic symptoms, with diagnostic errors reaching $40 \%$ of cases [15]. In the vast majority of cases, the clinic reports irritability and hyperactivity. BD presents a high risk of suicide attempts and substance abuse, the prognosis in adolescence being related to the evolution of these clinical pictures [16].

\section{Prevalence of bipolar disorder in children and adoles- cents}

The lifetime prevalence of BD in children and adolescents is $1 \%$, but that of BD sub syndromic is $5 \%$ [17]. In the majority of cases (85\%), BD immediately presents as mixed episodes; $80 \%$ of cases start with rapid cycles, and up to $60 \%$ of patients have initial psychotic symptoms. Finally, a high rate of comorbidity with ADHD is noted. Other studies have found a prevalence of $0.5 \%$ for children aged 5 to 9 years, increasing to $7.5 \%$ among prepubertal and pubertal children (10 to 14 years).

Several retrospective studies have focused on the unexpected precocity of the first episodes in adult bipolar patients: two studies found that 20 to $40 \%$ of adults with bipolar thought their disease began in childhood. A depressive episode in adolescence is associated with a three times higher risk of $\mathrm{BD}$ than in the adult population $(20-30 \%$ vs $10 \%)$ [18].

\section{Diagnostic difficulties}

The study of BD has progressed well since 1986, when Weller, et al. reported that the condition was underestimated and misdiagnosed in children and adolescents [19]. At that time, psychiatrists assumed that depression and bipolar mania did not exist in a child's psyche and that they rarely began until adulthood. Nonetheless, most European mental health professionals continue to believe that bipolar disorder rarely appears before adolescence. As a result, the first clinical manifestations may be misidentified. Aggression, mood swings, and irritability are often seen as symptoms of Attention Deficit Hyperactivity Disorder, or simply as conduct disorders. The main symptoms are manifested in the context of the school where academic difficulties, distractibility, hyperactivity become very significant for at least $90 \%$ of these children. They present considerable difficulties in dealing with criticism and overreact to bans and questioning of their behavior.

\section{The main points to built the diagnosis are}

1. Genetic factors (history of BD in one or both parents). The risk of developing bipolar disorder is four times higher when it has been diagnosed in one of the parents. However, contextual elements (living with an affected parent) and early trauma must also be taken into account.

2. Second, vulnerability linked to pregnancy (smoking in the mother), childbirth (prematurity), as well as psychological trauma during childhood. It has also been shown that these determine a more serious course (suicides) and a higher incidence of BD. A family history with a history of a first-degree relative affected together with a perinatal history may increase. the risk of developing $\mathrm{BD}$. The presence of these factors, especially in the context of clinical signs of affect and behavior disturbances, should alert the clinician to the search for a BD.

3. Thirdly, the diagnosis of BD should be considered in the presence of a family history of BD or mood disorders occurring in the context of conduct disorders, ADHD, abuse of toxic substances (cannabis in particular) or a history of suicide attempts.

4. Last but not least, we currently know that the presence of certain prodromes, although not specific, constitutes the common background of many young people affected.

\section{Comorbidity of BD in children and adolescents}

One of the essential characteristics of BD is that it presents a high degree of comorbidity with other clinical entities, moreover frequent in child psychiatry. A large proportion of children with bipolar disorder have two or more diagnoses. Some of the most common diagnoses include ADHD, oppositional disorder, conduct disorder, anxiety, and substance abuse [20].

* With clinical pictures presenting with irritability, the differential diagnosis includes OCD, major depression and Asperger's syndrome.

* With the recurring behaviors where aggression, irritability and explosiveness manifest themselves, BD must be differentiated from oppositional defiant disorder. 
* Finally, we must also think about borderline personality disorder in adolescents.

\section{Differential diagnosis}

Due to a co-morbidity of up to $90 \%$ in children under 12-year-old, BD must be differentiated from the various presentations of ADHD, which presents a challenge for the child psychiatrist. Between 70 and $90 \%$ of bipolar children also suffer from comorbid ADHD [21]. On the side of ADHD, in a prospective research of mood disorders in hyperactive patients, Biederman, et al. found a $23 \%$ prevalence of bipolar disorder [22]. The difficulty of the differential diagnosis is twofold: if the diagnostic inflation of recent years around ADHD has masked many bipolar children and adolescents under this diagnosis, it is necessary to avoid labeling real hyperactive children with the diagnosis of $\mathrm{BD}$ [23].

\section{Prodromal symptoms of BD in children and adolescents}

The first symptoms usually appear during adolescence, between 13 and 18 years old, with a peak incidence around the age of 14 [24]. They occur earlier in young people with a family history of $\mathrm{BD}$, and especially in those with bipolar heredity.

\section{Discussion}

Bipolar disorder in children and adolescents is poorly understood and underdiagnosed in the affected population.

We tried to define $\mathrm{BD}$, then we located it in relation to comorbidities with frequent psychopathological manifestations, such as ADHD, which allowed us to outline the prodromes and risk factors. Arrived at the last point of this article, we are able to delimit the essential parameters which contribute to the early diagnosis of $\mathrm{BD}$.

We can therefore say that the clinician should be particularly attentive when prodromal symptoms appear in children or adolescents from high-risk families (both parents), and this all the more so if the clinic also reports substance abuse and / or suicide attempts [25].

When children with a family history (genetic risk) and history of vulnerability exhibit these symptoms, the clinician should be alerted to the existence of $\mathrm{BD}$. It is therefore desirable to initiate an appropriate pharmacological treatment with the psychotherapeutic and family support measures essential in these situations. Further studies are needed to determine more specific prodromes at the individual, family and contextual level.

\section{References}

1. Pichot $P$ (1995) The birth of the bipolar disorder. Europ Psychiatry 10: 1-10. Link: https://bit.ly/2I2B6jq

2. Birmaher B (2013) Bipolar disorder in children and adolescents. Child Adolesc Ment Health 18: 140-148. Link: https://bit.ly/3ofaBXr

3. Regier DA, Kuhl EA, Kupfer DJ (2013) The DSM-5: Classification and criteria changes. World Psychiatry 12: 92-98. Link: https://bit.ly/3luu2tw

4. Singh T (2008) Pediatric bipolar disorder: diagnostic challenges in identifying symptoms and course of illness. Psychiatry (Edgmont) 5: 34-42. Link: https://bit.ly/36rrkk6

5. Krieger FV, Leibenluft E, Stringaris A, Polanczyk GV (2013) Irritability in children and adolescents: past concepts, current debates, and future opportunities. Rev Bras Psiquiatr 35: S32-S39. Link: https://bit.ly/39zRWkP

6. Danielyan A, Pathak S, Kowatch RA, Arszman SP, Johns ES (2007) Clinical characteristics of bipolar disorder in very young children. J Affect Disord 97 51-59. Link: https://bit.ly/3qlnMlg

7. Jensen PS, Youngstrom EA, Steiner H, Findling RL, Meyer RE, et al. (2007) Consensus report on impulsive aggression as a symptom across diagnostic categories in child psychiatry: implications for medication studies. J Am Acad Child Adolesc Psychiatry 46: 309-322. Link: https://bit.ly/2JDI1kp

8. Wagner KD, Hirschfeld RM, Emslie GJ, Findling RL, Gracious BL, et al. (2006) Validation of the Mood Disorder Questionnaire for bipolar disorders in adolescents. J Clin Psychiatry 67: 827-830. Link: https://bit.ly/2VmzzYy

9. Birmaher B, Axelson D, Strober M, Gill MK, Valeri S, et al. (2006) Clinica course of children and adolescents with bipolar spectrum disorders. Arch Gen Psychiatry 63: 175-183. Link: https://bit.ly/39wx9yC

10. Goldstein TR, Birmaher B, Axelson D, Ryan ND, Strober MA, et al. (2005) History of suicide attempts in pediatric bipolar disorder: Factors associated with increased risk. Bipolar Disord 7: 525-535. Link: https://bit.ly/3ofWrVX

11. Nurnberger JI, McInnis M, Reich W, Kastelic E, Wilcox HC, et al. (2011) A highrisk study of bipolar disorder. Childhood clinical phenotypes as precursors of major mood disorders. Arch Gen Psychiatry 68: 1012-1020. Link: https://bit.ly/2JA8v5k

12. Poznanski EO, Israël MG, Grossman J (1984) Hypomania in a four-year-old. Am Acad Child Adol Psychiatry 23: 105-110.

13. Weller RAS, Weller EBTSG, Fristad MA (1986) Mania in prepuberal children : Has it been under-diagnosed ? J Affect Disord 11: 151-154. Link: https://bit.ly/2JvWq14

14. Post RM, Altshuler LL, Kupka R, McElroy SL, Frye MA, et al. (2017) More childhood onset bipolar disorder in the United States than Canada or Europe: Implications for treatment and prevention. Neurosci Biobehav Rev 74: 204 213. Link: https://bit.ly/3oi9PJ0

15. Ballenger JC, Reus VI, Post RM (1982) The «atypical» clinical pictures of adolescent mania. Am J Psychiatry 139: 602-606.

16. Sala R, Axelson D, Birmaher B (2009) Phenomenology, longitudinal course, and outcome of children and adolescents with bipolar spectrum disorders. Child Adolesc Psychiatr Clin N Am 18: 273-289. Link: https://bit.ly/3mtGpaE

17. King CA, Berona J, Czyz E, Horwitz AG, Gipson PY (2015) Identifying adolescents at highly elevated risk for suicidal behavior in the emergency department. J Child Adolesc Psychopharmacol 25: 100-108. Link: https://bit.ly/3mAM7Yo

18. Rocha T, Zeni C, Caetano S, Kieling C (2013) Mood disorders in childhood and adolescence. Rev Bras Psiquiatr 35: S22-S31. Link: https://bit.ly/39BEjBM

19. Leibenluft E (2008) Pediatric bipolar disorder comes of age. Arch Gen Psychiatry 65: 1122-1124. Link: https://bit.ly/3lxlu3Q

20. Joshi G, Wilens T (2009) Comorbidity in pediatric bipolar disorder. Child Adolesc Psychiatr Clin N Am 18: 291-319. Link: https://bit.ly/2JF10iE

21. Narvaez J, Zeni C, Coelho R, Wagner F, Pheula G, et al. (2014) Does comorbid bipolar disorder increase neuropsychological impairment in children and adolescents with ADHD? Rev Bras Psiquiatr 36: 53-59. Link: https://bit.ly/2I2Adr6

22. Biederman J, Wozniak J, Kiely K, Ablon S, Faraone S, et al. (1995) CBC clinical scales discriminate prepubertal children with structured interview- 
derived diagnosis of mania from those with ADHD. J Am Acad Child Adolesc Psychiatry 34: 464-471. Link: https://bit.ly/3fXOSSE

23. Holtmann M, Duketis E, Poustka L, Zepf FD, Poustka F, et al. (2010) Bipolar disorder in children and adolescents in Germany: national trends in the rates of inpatients, 2000-2007. Bipolar Disord 12: 155-163. Link: https://bit.ly/37pvwAm
24. Danner S, Fristad MA, Arnold LE, Youngstrom EA, Birmaher B, et al. (2009) Early-onset bipolar spectrum disorders: diagnostic issues. Clin Child Fam Psychol Rev 12: 271-293. Link: https://bit.ly/2VodfNY

25. Findling RL, Stepanova E, Youngstrom EA, Young AS (2018) Progress in diagnosis and treatment of bipolar disorder among children and adolescents: an international perspective. Evid Based Ment Health 21: 177-181. Link: https://bit.ly/3lwbXuW
Discover a bigger Impact and Visibility of your article publication with Peertechz Publications

\section{Highlights}

* Signatory publisher of ORCID

* Signatory Publisher of DORA (San Francisco Declaration on Research Assessment)

* Articles archived in worlds' renowned service providers such as Portico, CNKI, AGRIS, TDNet, Base (Bielefeld University Library), CrossRef, Scilit, J-Gate etc.

* Journals indexed in ICMJE, SHERPA/ROMEO, Google Scholar etc.

* OAI-PMH (Open Archives Initiative Protocol for Metadata Harvesting)

* Dedicated Editorial Board for every journa

* Accurate and rapid peer-review process

* Increased citations of published articles through promotions

* Reduced timeline for article publication

Submit your articles and experience a new surge in publication services (https://www.peertechz.com/submission).

Peertechz journals wishes everlasting success in your every endeavours.

Copyright: (c) 2020 Bourin M. This is an open-access article distributed under the terms of the Creative Commons Attribution License, which permits unrestricted use, distribution, and reproduction in any medium, provided the original author and source are credited. 